\title{
COMPLEXIFICAÇÃO, FRAGMENTAÇÃO, DESEMPREGO ESTRUTURAL E A CRISE DO DIREITO DO TRABALHO: COMO DIAGNOSTICAR E SUPERAR AS DESIGUALDADES E PENSAR UM BRASIL JUSTO, A PARTIR DE UMA NOVA SOCIEDADE DO TRABALHO.
}

\section{COMPLEXITY, FRAGMENTATION, STRUCTURAL UNEMPLOYMENT AND LABOR LAW CRISIS: HOW TO DIAGNOSE AND OVERCOME INEQUALITIES AND THINK A FAIR BRAZIL, FROM A NEW SOCIETY OF WORK.}

\author{
${ }^{1}$ Isabele Bandeira De Moraes Dangelo \\ ${ }^{2}$ Everaldo Gaspar Lopes De Andrade
}

\section{RESUMO}

Pretende demonstrar o declínio do sistema protetivo tradicional, centrado no trabalho subordinado. As metamorfoses em curso desencadeia a clandestinização das relações de trabalho e o desemprego estrutural. Uma reconfiguração do Direito do Trabalho obedece a dois eixos fundamentais: a Economia Solidária e a Renda Universal Garantida. Da teoria econômica desenvolvimentista parte-se para e a teoria do decrescimento e, nesta direção, chega-se a três princípios do Direito do Trabalho. Por fim, a outra concepção protetiva envolvendo os novos atores sociais do novo mundo do trabalho. Uma proposta voltada para um modelo de sociedade e trabalho que vislumbra um Brasil mais justo.

Palavras-chave: Metamorfoses do trabalho, Desemprego estrutural, Economia solidária, Renda garantida, Proteção social

\begin{abstract}
It aims to demonstrate the decline of traditional protective system, centered on the child labor. Ongoing metamorphoses triggers clandestine of labor relations and structural unemployment. A reconfiguration of labor law follows two main axes: the Solidarity Economy and Income Guaranteed Universal. The developmental economic theory part and to the theory of degrowth, and in this direction, it reaches the three principles of labor law. Finally, the other protective design involving new social actors in the new world of work. A proposal focused on a model of society and work that envisions a fairer Brazil.
\end{abstract}

Keywords: Metamorphoses of work, Structural unemployment, Solidarity economy, Guaranteed income, Social protection

\footnotetext{
${ }^{1}$ Doutora em Direito pela Universidade Federal de Pernambuco - UFPE, Pernambuco (Brasil). Professora da Universidade Federal de Pernambuco - UFPE, Pernambuco (Brasil). E-mail: belebm@ hotmail.com

2 Doutor em Direito pela Universidade de Deusto, DEUSTO, Espanha. Professor de Direito do Trabalho na Universidade Federal de Pernambuco, Pernambuco (Brasil). E-mail: egasparandrade@uol.com.br
} 


\section{INTRODUÇÃO}

Os autores deste artigo pretendem de início salientar que as relações de trabalho subordinadas não correspondem a um fenômeno transhistórico. A supremacia deste modelo de sociedade começa a partir da queda do Absolutismo Monárquico, quando os poderes se encontravam nas mãos no clero e da nobreza e se verifica ascensão da burguesia ao poder e se institui o Estado Moderno. Ou melhor, quando se universaliza e se legitima a subordinação da força do trabalho ao capital como lócus privilegiado da sociabilidade e como a priori das teorizações, no âmbito da Sociologia Clássica, em geral, e do Direito do Trabalho, em particular.

Acontece que esta mesma Sociedade do Trabalho, centrada no trabalho contraditoriamente livre e subordinado, vivencia, nos dias atuais, uma metamorfose sem precedentes e se encontra afetada, sobretudo, por dois fenômenos: a subproletarização/desproletarização e o desemprego estrutural.

Trata-se, pois, uma crise sistêmica que afetou simultaneamente o Estado do Bem-Estar Social e o Pleno Emprego. Logo, redefinir as possibilidades e alternativas de trabalho e rendas para superar a crise do desemprego estrutural e, ao mesmo tempo, propor a reconfiguração teórico-dogmática dos fundamentos do Direito do Trabalho, a partir dos seus princípios, torna-se fundamental superar as desigualdades e pensar um Brasil justo a partir de uma nova Sociedade do Trabalho.

Encontra-se dividido em 4 (quatro) títulos, além da introdução e da conclusão, e assim distribuídos: As Evidências Empíricas Confirmadoras da Heterogenização, Complexificação, Fragmentação e Subproletarização; As Alternativas para Superar as Desigualdades, a partir de uma Nova Sociedade do Trabalho; A Teoria do Decrescimento. Uma Opção às Alternativas Tradicionais de Desenvolvimento Destrutivo e o último - Os Princípios da Proteção Social, da Democratização da Economia e do Trabalho e do Direito do Trabalho como Direito Humano Fundamental.

\section{AS EVIDÊNCIAS EMPÍRICAS CONFIRMADORAS DA HETEROGENIZAÇÃO, COMPLEXIFICAÇÃO, FRAGMENTAÇÃO E SUBPROLETARIZAÇÃO.}

As expressões HETEROGENIZAÇÃO, COMPLEXIFICAÇÃO, FRAGMENTAÇÃO e SUBPROLETARIZAÇÃO foram grafadas pelo Sociólogo da UNICAMP Ricardo Antunes (2006). A Partir de dados estatísticos que, a cada dia, confirmam as hipóteses por ele 
assinaladas, registra as metamorfoses sofridas pelo mundo do trabalho contemporâneo que transformaram por completo o interior das organizações produtivas - heterogenização, complexificação, fragmentação -, e apontam, também, para rupturas impactantes experimentadas fora ou para além do interior das organizações - clandestinização, fruto da supremacia do trabalho precário - e o aparecimento de algo ainda mais impactante: o desemprego estrutural.

Segundo Ricardo Antunes (2006), entre 1982 e 1988, deu-se, na França, uma redução de 501.000 empregos por tempo completo, e houve um aumento de 111.000 de empregos em tempo parcial; já na França, Alemanha, Estados Unidos e Inglaterra aproximadamente 35\% a $50 \%$ da população ativa encontravam-se desempregada ou desenvolvendo trabalhos precários, parciais. (ANTUNES, 2006) A propósito, o diagnóstico apresentado pelo Prof. Everaldo Gaspar Lopes de Andrade (1995), em 1995, fazendo referência ao quadro do desemprego dos países da OCDE, constituídos pela Áustria, Bélgica, Canadá, Dinamarca, França, Alemanha, Grécia, Islândia Irlanda, Itália, Luxemburgo, Holanda, Noruega, Portugal, Suécia, Espanha, Suíça, Turquia, Reino Unido, Estados Unidos, Japão, Finlândia, Austrália e Nova Zelândia, pesquisados em 1994, apresentava os seguintes números.

\begin{tabular}{|c|c|c|c|c|c|}
\hline & $81 / 90$ & 91 & 92 & 93 & 94 \\
\hline Alemanha & 2,1 & 2,6 & 3,0 & 3,9 & 4,4 \\
\hline Estados Unidos & 8,2 & 8,4 & 9,4 & 8,9 & 8,4 \\
\hline Japão & 1,5 & 1,4 & 1,4 & 1,7 & 1,8 \\
\hline $\begin{array}{c}\text { Outras potências } \\
\text { Europeias }\end{array}$ & 7,4 & 7,4 & 7,9 & 8,3 & 8,6 \\
\hline $\begin{array}{c}\text { Países mais ricos } \\
\text { do mundo }\end{array}$ & 20,3 & 21,2 & 23,3 & 24,4 & 24,7 \\
\hline $\begin{array}{c}\text { Pequenos países } \\
\text { da Europa }\end{array}$ & 7,1 & 7,2 & 8,1 & 9,6 & 10,0 \\
\hline $\begin{array}{c}\text { TOTAL DA } \\
\text { OCDE }\end{array}$ & 28,1 & 29,4 & 32,5 & 35,1 & 35,7 \\
\hline
\end{tabular}

Quadro 1: Número de Desempregados (em milhões) Fonte: ANDRADE, Everaldo Gaspar Lopes de Andrade. Direito do trabalho: Ensaios filosóficos, vol. 2. São Paulo: LTr, 1995, p. 26 


\begin{tabular}{|c|c|c|c|c|c|}
\hline & $81 / 90$ & 91 & 92 & 93 & 94 \\
\hline Alemanha & 7,1 & 6,7 & 7,7 & 10,1 & 11,3 \\
\hline Estados Unidos & 7,1 & 6,7 & 7,4 & 7,0 & 6,5 \\
\hline Japão & 2,5 & 2,1 & 2,2 & 2,5 & 2,6 \\
\hline $\begin{array}{c}\text { Outras potências } \\
\text { Europeias }\end{array}$ & 9,8 & 9,5 & 10,3 & 10,9 & 11,1 \\
\hline $\begin{array}{c}\text { Pequenos países } \\
\text { da Europa }\end{array}$ & 10,0 & 9,6 & 12,6 & 12,5 & 12,9 \\
\hline $\begin{array}{c}\text { TOTAL DA } \\
\text { OCDE }\end{array}$ & 7,5 & 7,2 & 7,9 & 8,5 & 8,6 \\
\hline
\end{tabular}

Quadro 2: Taxa de Desemprego (\% população ativa) Fonte: ANDRADE, Everaldo Gaspar Lopes de Andrade. Direito do trabalho: Ensaios filosóficos, vol. 2. São Paulo: LTr, 1995, p. 26

É neste cenário do trabalho que o mundo passa a vivenciar as administrações flexíveis e a reengenharia - enxugamento de custos, cortes radicais da mão-de-obra, ${ }^{1}$ em que nenhum setor do trabalho pode evitar ser alcançado pelo fantasma do desemprego, do trabalho temporário, da precarização e da terceirização. Como afirma István Mészáros (2006): “Na verdade o 'trabalho temporário' é chamado, em algumas línguas, de 'precarização', apesar de, na maioria dos casos, seu significado ser tendenciosamente deturpado como 'emprego flexível"” (MÉSZÁROS, 2006, p. 27). ${ }^{2}$

\footnotetext{
${ }^{1}$ Esta visão analítica envolve pesquisadores vinculados a vários programas de pós-graduação em direito, como o Programa de Pós-graduação em Direito da Universidade Federal de Pernambuco e ao Grupo de Estudos Direito do Trabalho e Teoria Social Crítica daquele programa, em que se torna possível constatar a fragilidade da produção literária sobre o tema flexibilização produzida pela comunidade jurídica, especialmente nos manuais. É que ela aparece quase sempre como causa e não como consequência dos modelos de administração científica ou como se não estivesse vinculada a evolução da chamada administração científica. Flexibilização e desregulamentação que legitimam a terceirização, para os estudos que foram desenvolvidos sobretudo naquele Programa de Pós-graduação da Faculdade de Direito do Recife, retratam criticamente a sofisticada evolução do capitalismo e denuncia a produção acadêmica a serviço dessa mesma produção capitalista e as formas de gestão de gestão que procura se adaptar as novas exigências de um mercado cada vez mais global. A propósito, consultar a obra: DRUCK, Graça; FRANCO, Tânia. A Perda da Razão Social do Trabalho: Terceirização e precarização. São Paulo: Boitempo, 2007.

${ }^{2}$ Este é o quadro geral do desemprego no mundo. A previsão já era desoladora para o ano de 2010, conforme o Relatório Mundial sobre o Emprego, elaborado pela OIT: "O Relatório de 2010 - da
} 


\section{AS ALTERNATIVAS PARA SUPERAR AS DESIGUALDADES, A PARTIR DE UMA NOVA SOCIEDADE DO TRABALHO.}

A reconfiguração da Sociedade do Trabalho, diante das metamorfoses em curso, implica a ampliação dos sentidos protetores, que devem transitar por aspectos que vão além do trabalho livre/subordinado e da maneira como os autores deste artigo se comprometem a narrar por meio das seções subsequentes.

\subsection{O destaque para a Economia Social e Solidária.}

Os autores deste artigo incluem a Economia Social e Solidária no contexto do alargamento do sistema protetivo de relações de trabalho, para que ele possa ir além do trabalho contraditoriamente livre e subordinado. Neste sentido, para Isabele D`Angelo (2014), o trabalho cooperado deve ser inserido no sistema de proteção, sob três argumentos: a) para quando aparecer disfarçado, destinado a fraudar a lei, ser devidamente combatido; b) para protegê-lo, sempre que pessoas ou instituições coloquem em risco a sua credibilidade ou a sua validade, enquanto forma alternativa à subordinação da força do trabalho ao capital; c) reconhecer as unidades coletivas de trabalho geridas de forma cooperada e autônoma, não tipificadas como propriedade privada e individualizada dos meios de produção. (DANGELO, 2004)

Vilma Margarete Simão (2011) parte das experiências vividas em três cooperativas Blumenau, Criciúma e Joinville - e estabelece uma concepção de argumentativa de raiz marxista. Daí justifica a cooperação econômica e a autogestão. Lembra o professor Valmor Schiocher, ao prefaciar a aludida obra, que

Organização Internacional do Trabalho (OIT) sobre Tendências Mundiais de Emprego - constata que o número de pessoas sem emprego no mundo atingiu quase 212 milhões em 2009, com um aumento sem precedentes de 34 milhões comparativamente a 2007, nas vésperas da crise global. Com base em previsões do FMI, a OIT calcula que o desemprego a nível mundial vai permanecer elevado em 2010. A OIT apresentou recentemente um Relatório sobre o estado atual da crise mundial do emprego que examina o estado atual dos mercados de trabalho a nível mundial neste período de crise econômica, e analisa as repercussões econômicas e sociais de um eventual abandono dos planos de relançamento e das medidas de apoio ao emprego. Já o relatório "Perspectivas para o emprego e o social no mundo Tendências para 2015", o desemprego no Brasil também deverá ser de 7,3\%, em 2017, o mesmo índice do ano anterior. As taxas de desemprego previstas em relação ao Brasil em 2015 e nos dois próximos anos se situam acima da média mundial e também dos índices médios na América Latina e Caribe e dos países do G20, grupo que reúne as principais economias do planeta, entre elas, o Brasil. Fonte: http://www.ilo.org. 
Desta forma é emblemática e afirmação seminal de Paul Singer da autogestão como forma de combate ao desemprego. A cooperação e ato gestão se apresentam como estratégia não capitalista daqueles/as-que-vivemdo-trabalho (expressão de Ricardo Antunes) para sua sobrevivência diante de uma tragetória interrompida de trabalho assalariado ou mesmo de negação da expectativa da participação nesta tragetória para milhões de pessoas. No entanto, mais do que uma forma de reseliência trata-se igualmente de uma experiência pedagógica na elaboração de estratégias no permanente e contraditório conflito com a lógica econômica dominante. Daí a busca de novos sentidos e significados para uma economia fundamentada na cooperação, na solidariedade e na autogestão (SIMÃO, 2011, p. 12).

Reconhece ser incomum o trabalhador dirigir a renda obtida por meio de salário e, ao fazer reservas, poupar, adquirir meios de produção, objetivando libertar-se da alienação do resultado do seu trabalho para fazer com que seus produtos permanecerem seus, embora possa ocorrer em meio a uma sociedade capitalista, "que assalaria e usurpa o trabalhador do resultado do seu próprio trabalho" (idem, p. 223). Daí poder constatar que trabalhadores foram capazes de criar unidades coletivas de trabalho e passaram a gerir as mesmas de modo cooperado e autônomo. Neste aspecto,

Coletivas, porque as unidades foram constituídas por um grupo de trabalhadores, sem a presença da propriedade privada e individualizada do meios de produção e presença por um patrão e, portanto, com trabalho isento da presença do capital acumulado, com uso de mais-valia, trabalho assalariado [...] Assim, na prática, negam o capital como resultado da apropriação do excedente do trabalho por um proprietário dos meios de produção. Os trabalhadores conquistaram as condições objetivas de produção por meio do próprio trabalho [...] não anteciparam o dinheiro para adquirir os meios de produção e contratar capacidade de trabalho na condição de assalariado; também não possuíam um dinheiro a ser transformado em capital por meio do trabalho excedente na forma de mais valia (Idem, pp. 223-224).

Tanto a aludida autora quando Boaventura de Souza Santos (2005) ressaltam que as lutas contemporâneas, desencadeadas sobretudo nos países periféricos ou semiperiférico, contra a exploração dos seus povos ancestrais, passam por vários movimentos operários, o que significa um combate historicamente sem tréguas ao capitalismo. Fenômeno que tem se tornado um desafio acompanhado, segundo Boaventura e Souza Santos e César Rodríguez, de

uma vasta tradição de pensamento crítico - desde o pensamento associativo de Saint-Simon, Fourier e Owen, na Europa, no século XIX, até a reivindicação de um marxista do capitalismo industrial - que impulsionou o debate sobre formas de sociedade mais justas que sejam alternativas viáveis às sociedades capitalistas (SANTOS e RODRIGUEZ, 2005, p. 24-25). 
Estas as razões pelas quais a Economia Solidária deve integrar o sistema protetivo do Direito do Trabalho e sempre que houver ameaça a seus postulados, seja por iniciativas externas ou internas de qualquer natureza, este campo do conhecimento jurídico deve produzir as normas destinadas a preservação, como afirmam Boaventura e Souza Santos e César Rodríguez, de "formas de organização baseadas na igualdade, na solidariedade e na proteção do meio ambiente" (Idem, p. 24). O que implica a radicalização da democracia participativa e da democracia econômica enquanto faces da mesma moeda. Para eles,

\begin{abstract}
Uma das características emancipatórias das alternativas de produção não capitalista consiste no seu potencial para substituir a autocracia típica da produção capitalista - pela democracia participativa no interior das unidades de produção Em outras palavras, o objetivo é estender o campo de ação da democracia do campo político para o campo econômico e apaga, desta forma, a separação artificial entre política e economia que o capitalismo e a economia liberal estabeleceram (Idem, p. 69).
\end{abstract}

\title{
3.2 A taxação dos fluxos financeiros internacionais e adoção de uma Renda Universal Garantida.
}

A professora Juliana Teixeira Esteves (2015), estudando com profundidade os dois sistemas de seguridade social existentes ou a dualidade que passou a imperar a partir da década de 70, quando o neoliberalismo começou a ser instituído na esfera global, chega a conclusão segundo a qual ambos os regimes - o público e o privado de seguridade social - se encontravam em crise e não tinham a mínima possibilidade de abrigar e proteger aqueles que estão afetados pelo subemprego, o trabalho clandestino e o desemprego estrutural.

A seguridade social tradicional só foi capaz de manter-se hegemônica porque, no auge do Estado do Bem-estar Social, a maioria da população economicamente ativa encontrava-se envolvido no Pleno Emprego. No auge deste sistema, empregado e empregador contribuíam para manter o Estado do Bem-estar. Agora, este universo fica reduzido à metade da população economicamente ativa. Logo, se a adoção de um plano de previdência privada implica também uma contribuição mensal, aquela metade que se encontra fora do mercado tradicional de trabalho e alcançado pelo subemprego ou o desemprego estrutural, não tem também a capacidade contributiva para participar nem deste e nem daquele sistema de seguridade social.

É exatamente neste contexto que autora aponta, como alternativa, a adoção de uma renda universal garantida, a partir da taxação dos fluxos financeiros internacionais e, aqui, também pela taxação das grandes fortunas. A aludida professora inicia sua narrativa 
promovendo uma incursão pela história deste instituto, desde a fase pré-capitalista aos nossos dias.

Para ela, na atualidade, diversos são os autores, nos quais se pode encontrar a ideia da criação de uma verba que seja destinada a todos os cidadãos, com o objetivo de garantir a manutenção das condições mínimas da dignidade. Tal verba seria paga pelo Estado a todo e qualquer cidadão, independentemente de classe social ou condição financeira. A fonte de custeio de tal "assistencialismo" ainda tem sido debatida por sociólogos, economistas e juristas e sua motivação depende da forma como se entende ser a natureza da verba: natureza política, ética ou econômica.

A propósito, uma matéria veiculada em 25 de agosto de 2015, no site da BBC Brasil dá conta de que o governo Finlandês estuda aplicar um projeto piloto a partir do qual será garantida uma renda mínima a todos os seus cidadãos independentemente de situação de trabalho. Não há nada ainda decidido acerca do valor a ser pago, ou quais os requisitos para ser beneficiário da medida, todavia o alvo do projeto são os desempregados uma vez que, na Finlândia, o desemprego atinge $10 \%$ da força de trabalho, cerca de 280 mil pessoas. O argumento central é que o benefício possa reduzir e simplificar os gastos com a seguridade social. Outros países tem estudado a aplicação de semelhantes medidas:

Medidas semelhantes foram adotadas em outros países da Europa. Em Utrecht, na Holanda, um pagamento mínimo começará a ser realizado para toda a população a partir de setembro.

No Reino Unido, o Partido Verde propôs uma iniciativa parecida a todos os cidadãos britânicos durante o último processo eleitoral.” (BBC Brasil, 2015)

A renda básica de cidadania vem paulatinamente adquirindo forma. No Brasil, se encontra ampara na legislação, com o nome de Renda Mínima. É preciso ressaltar que,

Nos últimos trinta anos, a desigualdade na distribuição dos rendimentos entre países aumentou dramaticamente. A diferença de rendimento entre o quinto mais rico e o quinto mais pobre era, em 1960, de 30 para 1 , em 1990, de 60 para 1 e, em 1997, de 74 para 1 . As 200 pessoas mais ricas do mundo aumentaram para mais do dobro a sua riqueza entre 1994 e 1998. A riqueza dos três mais ricos bilionários do mundo excede a soma do produto interno bruto dos 48 países menos desenvolvidos do mundo (PNUD, 2001). (SANTOS, 2011, p. 34)

O sociólogo Zygmunt Bauman (2015), na introdução de sua obra A Riqueza de Poucos Beneficia Todos Nós? Traz dados ainda mais alarmantes: 
Um estudo recente do World Institute for Development Economics Research da Universidade das Nações Unidas relata que o $1 \%$ mais rico de adultos possuía $40 \%$ dos bens globais em 2000, e que os $10 \%$ mais ricos respondiam por $85 \%$ do total da riqueza do mundo. A metade situada na parte mais baixa da população mundial adulta possuía $1 \%$ da riqueza global. Contudo, essa é apenas uma foto instantânea do processo em curso. A cada dia, avultam-se sem parar informações ainda piores para a igualdade humana e também para a qualidade de vida de todos nós. (BAUMAN, 2015, p. 9)

Recente estudo publicado pela organização não-governamental britânica Oxfam da conta de que os bens acumulados pelo $1 \%$ mais rico do planeta ultrapassarão a riqueza do resto da população mundial.

A riqueza desse $1 \%$ da população subiu de $44 \%$ do total de recursos mundiais em 2009 para 48\% no ano passado, segundo o grupo. Em 2016, esse patamar pode superar $50 \%$ se o ritmo atual de crescimento for mantido. (BBC Brasil, 2015)

Afirma Claus Offe (1991) que

Apesar dos inegáveis progressos das condições de vida dos trabalhadores, a estrutura institucional do Estado social não tem contribuído, ou tem bem pouco, para modificar a distribuição de renda entre as duas classes do capital e do trabalho. A enorme maquinaria da redistribuição não trabalha no sentido vertical, mas no horizontal, ou seja, dentro da classe dos operários. Outro aspecto dessa ineficácia é que o Estado social não elimina as causas dos casos de necessidade e carências (como, por exemplo, doenças profissionais, a desorganização das cidades pelo mercado capitalista de imóveis, o desgaste da capacidade e da qualificação do trabalho, o desemprego, etc.), mas apenas compensa (parcialmente) as conseqüências dessas ocorrências (pondo à disposição serviços de saúde e seguros, subvenções habitacionais, organizações educacionais e reeducacionais, auxílio desemprego e similares). Em termos gerais, o modo do intervencionismo social, típico do Estado social, vem sempre "tarde demais" e, consequentemente, as suas medidas posteriores são mais caras e menos efetivas do que permitiria um modo "causal" de intervenção. É este o dilema, universalmente conhecido, da política social, cuja resposta padronizada é a recomendação de que se adotem estratégias “preventivas.(OFFE, 1991, p.122)

Já Raventós (1999) defende um Subsídio Universal Garantido, pago pelo governo ou pelo estado aos cidadãos que gozem de seus direitos na sociedade, que queira ou não trabalhar 
de forma remunerada, independente de estado civil, classe social ou condições financeiras. Segundo sua proposta:

El subsidio Universal Garantizado es un ingreso pagado por el gobierno a cada miembro de pleno derecho de la sociedad, incluso si no quiere trabajar de forma remunerada, sin tomar en consideración si es rico o pobre, o dicho de outra forma, independientemente de sus otras posibles fuentes de renta, y sin importar con quién conviva (RAVENTÓS, 1999, p.47)

Raventós recebeu várias críticas, mesmo daqueles que apoiam a ideia a partir de outras denominações, dentre elas o dividendo social, a renda básica, a renda de cidadania, o ingresso garantido. A expressão em francês recebe duas nomenclaturas de maior circulação: revenue universelle e revenue de citoyenneté. Em inglês, o instituto é tratado sob a denominação de basic income. A justificativa para tal pagamento é simples: vive-se numa sociedade que gera riquezas e pobrezas e o desemprego é estrutural.

A repercussão e importância desta alternativa foram realçadas pelo Jornal El País, em 02 de janeiro de 2000:

Es necesario también imaginar una nueva distribución del trabajo y de las rentas en una economía plural en la que el mercado ocupe solo uma parte del espacio, con un sector solidario y un tiempo libre cada vez más importante. Hay que establecer una renta mínima incondicional para todos, concedida a todo individuo desde el nacimiento sin condición alguna de situación familiar ni profesional. Este principio, revolucionario, consiste en que se tiene derecho a esta renta de existencia por el simple hecho de existir, y no para existir. Su instauración se basa en la idea de que la capacidad productiva de una sociedad es el resultado de todo el saber científico e técnico acumulado por las generaciones anteriores. En efecto, los frutos de ese patrimonio común han de revertir en el conjunto de individuos bajo forma de una renta básica incondicionada. Debería ampliarse a toda la humanidad, pues ya ahora el producto mundial equitativamente distribuido bastaría para asegurar una vida confortable al conjunto de todos los habitantes del planeta (El País, 02/01/00)

Já o financiamento do subsídio pode ser feito a partir da taxação do capital especulativo. A implantação de uma renda básica, ou SUG como prefere Raventós (1999), favorece a expansão da liberdade como não-dominação da cidadania e liberdade da tradição republicana. Por isso, um estado republicano comprometido com o progresso da liberdade, estará interessado numa política que fomente a independência sócio-econômica dos cidadãos. A instauração de um SUG confere uma independência ao indivíduo que lhe permite estar menos sujeito às influências de dominação. A existência de uma renda básica constitucionalmente garantida proverá o indivíduo de um direito à existência que alcançaria, com intensidade, a liberdade como não-dominação. 


\subsection{O diagnóstico da taxação das Grandes Fortunas.}

A História mostra que, no desenrolar do século XX, os países que se preocuparam em adotar um sistema de tributação progressiva sobre renda, riqueza e heranças, foram bem sucedidos em desconcentrar continuamente renda e riqueza.

Quase todos os países da Europa Ocidental já adotaram um imposto desta natureza. Até as sociedades mais liberais, a exemplo do Reino Unido e dos Estados Unidos, instituíram uma forte tributação sobre heranças, o que contribuiu bastante para equilibrar problemas distributivos.

Informações constantes em estudo do IPEA $^{3}$ nos anos 1990, todos esses países já alcançavam um bom nível de desenvolvimento e de igualdade e, muitos deles, optaram por abolir o imposto sobre riqueza, mas, atualmente, já estudam voltar a adotar a taxação, como a Suécia.

Por outro lado, em alguns países essa tributação foi mantida, como França, Uruguai e Argentina, houve tendência de crescimento da arrecadação e do número de contribuintes. Esses países, com o passar dos anos, desenvolveram uma legislação e administração bem detalhada e complexa. Recentemente, países como Islândia e Espanha reinstituíram o imposto como resposta à crise financeira e fiscal que tem assolado a Europa desde 2009.

Atualmente, na Europa, a Holanda, França, Suíça, Noruega, Islândia, Luxemburgo, Hungria e Espanha possuem o imposto sobre riqueza. Cada país possui uma estrutura de taxação diferente, mas o resultado comum é a cobrança de impostos sobre os patrimônios mais elevados. A França é o caso de maior destaque, pois além de possuir um "Imposto de Solidariedade sobre a Fortuna" (inspiração do prospectivo Imposto sobre Grandes Fortunas no Brasil), em 2012 aprovou um imposto especial - válido por dois anos - de $75 \%$ sobre os altos rendimentos superiores a um milhão de euros por ano. (Sul 21, 2015)

Nos Estados Unidos, o tema é assunto recorrente. O imposto sobre heranças já é bem elevado no país (30\%), sobretudo quando comparado com o do Brasil (4\%). No Reino Unido a propriedade (imobiliária) é, muitas vezes, o principal ativo nas mãos dos mais ricos, e tem sido muito taxada.

Na América do Sul, Argentina (desde 1972), Uruguai (desde 1991) e Colômbia (desde 1935), são exemplos de países que tributam progressivamente a riqueza.

\footnotetext{
${ }^{3}$ Nota técnica. As discussões sobre a regulamentação do Imposto sobre Grandes Fortunas: a situação no Brasil e a experiência internacional.
} 
A discussão sobre um sistema tributário mais justo e eficiente é recorrente no mundo todo e, ao avaliar experiência dos outros países, algumas conclusões podem ser aplicadas à questão brasileira. O patamar de desigualdade, considerado com o tamanho da economia, o nível de tecnologia e a baixa tributação de heranças e de propriedades, neste país, são fatores que indicam que a tributação de grandes fortunas deve ser efetivada.

Atualmente, $56 \%$ dos impostos brasileiros são cobrados indiretamente, como nos produtos das prateleiras do supermercado, de modo que ricos e pobres, neste momento, pagam de modo igual. É o imposto de consumo. Como o brasileiro mais pobre gasta a maior parte de sua renda em consumo, paga mais impostos. Considerando apenas essa tributação indireta, a carga dos mais pobres é de $29,1 \%$, contra $10,7 \%$ dos mais ricos.

Se os impostos no Brasil tivessem o propósito de taxar a riqueza, a partir de impostos sobre transferências bancárias ou heranças, seria possível começar a equilibrar essa conta. Apenas a título de exemplo, no ranking das famílias mais ricas do mundo, o Brasil está em $7^{\circ}$ lugar, assustadoramente acima de países como Holanda, Suíça e Argentina, os quais tributam riqueza.

A tributação de grandes fortunas, conforme Thomas Piketty (2014):

trata-se de uma questão global. Enquanto houver paraísos fiscais, a taxação dos mais ricos sempre será um desafio, em qualquer lugar do mundo. Mesmo assim, em um país tão desigual em termos de renda e riqueza, como o Brasil, esse imposto poderia ser um primeiro passo.. (PIKETTY, 2014, p. 58)

\section{A TEORIA DO DECRESCIMENTO. UMA OPÇÃO ÀS ALTERNATIVAS TRADICIONAIS DE DESENVOLVIMENTO DESTRUTIVO.}

A questão ambiental tem sido uma das principais problemáticas nos debates sobre o futuro da humanidade. As discussões em torno dos limites físicos do planeta não se restringem a um pequeno número de países e de profissionais, sendo um campo vasto para análises, propostas de ação e produção acadêmica. Foi neste cenário que desabrochou a teoria do decrescimento. Um conceito que um grupo de mentes com uma pauta ecológica resgatou do título de uma coleção de ensaios do matemático romeno Nicholas Georgescu-Roegen (1971). A palavra decrescimento foi escolhida com o propósito de provocar, a fim de acordar as consciências. O professor Serge Latouche (2009) em suas obras afirma incessantemente que é necessário sair da religião do crescimento. Por meio desta linha de pensamento surgiu um movimento que luta contra a cultura do usar e jogar, da obsolescência programada, o 
crédito sem limites e tantos atropelos que ameaçam o futuro do planeta. Latouche, professor de economia na Universidade de Paris-Sud XI, se contrapõe àquele modelo clássico de crescimento. O livro Pequeno Tratado do Decrescimento Sereno, foi escrito a partir da ideia de produzir um compêndio das análises já disponíveis sobre o decrescimento. ${ }^{4}$

Nicholas Georgescu-Roegen, com a obra The Entropy Law and the Economic Process é precursor da chamada bioeconomia. Atento às questões sobre a sobrevivência da vida na Terra, foi uns dos primeiros em evidenciar a relação entre a lei da entropia e os processos econômicos. Mais tarde, estabelece o termo decrescimento em (La décroissance: Entropie Écologie - Économie, 1975), como um passo inevitável para um desenvolvimento verdadeiramente sustentável. Logo, Herman Daly - Steady-State Economics (1977) - por sua vez, propôs a necessidade de deslocar a economia para um "estado estacionário", no qual a escala da produção não fosse além da capacidade natural de suporte dos ecossistemas. Isso implicaria numa mudança de foco da política econômica, com vistas a um desenvolvimento sustentável. $^{5}$

Latouche qualifica o sistema capitalista como uma sociedade "fagocitada" por uma economia cujo único propósito é o crescimento pelo crescimento. Como consequência, o sistema despreza relatórios aterradores, que alertam estar chegando ou ultrapassando os limites de nosso planeta. Para enfrentar esta situação, Latouche propõe três passos fundamentais: "Avaliar o alcance do decrescimento, propor, como alternativa, a utopia concreta do decrescimento, e especificar os meios de sua realização" (LATOUCHE, 2009, p. $\mathrm{XV})$. O decrescimento objetiva acabar com o "jargão politicamente correto dos drogados do produtivismo" (LATOUCHE, 2009, p. 4). Neste ponto, é importante não confundir o decrescimento com um crescimento negativo. De fato, a diminuição do crescimento afunda as nossas sociedades na incerteza, desemprego, abandono de programas sociais, sanitários, educativos, culturais, entre outros. Para melhor entender o conceito, é preciso entender

\footnotetext{
4 Assim, na sequência da analise que realizada em Survivre au développement e, depois, em Le Pari de la decroissance, o autor integra novas reflexões, em particular os debates realizados pela revista Entropia. É, portanto, uma ferramenta de trabalho útil para estudantes, cientistas, gestores e participantes de movimentos sociais ou políticos, em particular, do plano local ou regional.

5 Mais recentemente, autores como Jean-Claude Besson-Girad (Decrescendo Cantabile: Petit Manuel pour une décroissance harmonique, 2005) e Paul Aries (Décroissance ou barbárie, 2005) trazem a discussão do decrescimento como uma proposta concreta para uma mudança civilizacional, em resposta à crise social, política, econômica e ecológica. Nesse âmbito, Latouche hoje é referência. Seu trabalho vem precedido por uma ampla variedade de publicações.
} 
também que o decrescimento não faz parte do desenvolvimento sustentável. Ele surge para sair das confusões desse campo.

A sociedade de acumulação ilimitada está condenada ao crescimento, baseado na "publicidade, o crédito e a obsolescência acelerada e programada dos produtos" (LATOUCHE, 2009, p. 17). Calcula-se que a humanidade consome quase $30 \%$ acima da capacidade de regeneração da biosfera. Para aliviar esta situação, coloca-se inclusive a possibilidade do "controle massivo da população ou a redução, principalmente do terceiro mundo" (Idem, p. 31). Contudo, o problema não é o superpovoamento, mas saber dividir os recursos de maneira equitativa e ética. Latouche afirma que nos encontramos, hoje, na beira da catástrofe e que é preciso uma reação rápida e muito enérgica para mudar o rumo.

Um segundo passo para o decrescimento é compreender que ele é uma utopia concreta assim como uma proposta revolucionária para se viver melhor. Desta forma, o decrescimento longe de se refugiar no irreal, tenta explorar as possibilidades objetivas de sua aplicação, como um projeto político. É nesse ponto que o autor faz a sua maior contribuição: uma proposta concreta de como entrar num "circulo virtuoso" de decrescimento sereno, representado por oito mudanças interdependentes que se reforçam mutuamente: reavaliar, reconceituar, reestruturar, redistribuir, relocalizar, reduzir, reutilizar, reciclar (Ibidem, p. 42).

\section{OS PRINCÍPIOS DA PROTEÇÃO SOCIAL, DA DEMOCRATIZAÇÃO DA ECONOMIA E DO TRABALHO E DO DIREITO DO TRABALHO COMO DIREITO HUMANO FUNDAMENTAL.}

Os adeptos da teoria jurídico-trabalhista crítica têm procurado articular os novos princípios do Direito do Trabalho com experiências que vão além do trabalho subordinado. Aqui, expõem-se três deles, objetivando inseri-los com as alternativas superadoras das crises específicas que afetam o trabalho em geral e do Direito do Trabalho, em particular. Neste contexto, apresenta-se uma pauta hermenêutica distinta e novos fundamentos teóricofilosóficos, o que impõe ao tema um verdadeiro corte epistemológico. Sobretudo por aparecerem como fundamento de validade deste campo do conhecimento jurídico e colocarem em relevo as relações sindicais sobre as relações individuais. Para o caso em apreço, lança-se mão de três princípios: 
a) O Princípio da Proteção Social e seu impacto na reconfiguração da teoria jurídica do salário.

É preciso considerar, de início, a importância do Princípio da Proteção originariamente formulado pelo jurista uruguaio Américo Plá Rodrigues ${ }^{6}$ (2000), sobretudo, os seus caracteres de irrenunciabilidade, inderrogabilidade, indisponibilidade e ordem pública. Mas aqui se pretende questionar a versão reducionista daquela proposta, posto que a mesma se encontra condicionada ou limitada à proteção do contrato individual de trabalho. Este princípio protetor deve ser alargado, para alcançar todas as possibilidades e alternativas de trabalho e rendas compatíveis com a dignidade humana.

É o que se pode deduzir dos pormenorizados argumentos contidos naquela obra específica (2008). Princípios que, por seu turno, se articulam com próprio conceito de Direito Individual de Trabalho e nos seguintes termos:

Ramo do Direito do Trabalho destinado ao disciplinamento, à proteção e à manutenção de todas as possibilidades e alternativas de trabalho e rendas que atendam ao bem-estar, à dignidade $\mathrm{e}$ ao desenvolvimento sócio-cultural da pessoa humana. (ANDRADE, 2005, p. 368)

Deixa-se transparecer que um verdadeiro Princípio de Proteção Social emerge da força das organizações coletivas e de uma proposta econômica adaptada à sociedade pós-industrial, "a fim de atender indistintamente a todos os cidadãos que vivem ou pretendem viver de uma renda ou de um trabalho dignos, sobretudo o trabalho livre" (ANDRADE, 2008, p. 216).

b) O Princípio da Democratização do da Economia e do Trabalho.

Este princípio se transforma no segundo argumento capaz de ampliar os pressupostos teóricos da inclusão de todas as alternativas de trabalho e rendas e não apenas do trabalho subordinado.

\footnotetext{
${ }^{6}$ Sobre o assunto, Princípios do Direito do Trabalho - Américo Plá Rodriguez é considerado responsável pela compilação dos princípios fundamentais do Direito do Trabalho. Conferir em: RODRIGUEZ, Américo Plá. Princípios de Direito do Trabalho. São Paulo: LTR, 2000.
} 
Daí é possível encontrar dois argumentos filosóficos que expressam uma preocupação dirigida a ultrapassar a versão reducionista da proteção ao trabalho subordinado. O primeiro, parte para enfrentar as versões utilitaristas de justiça e recepcionar a ética discursiva. Neste contexto, assume uma atitude crítico-hipotética, através do processo discursivo, onde se pode constatar a influência da filósofa Adela Cortina (2005), para rejeitar o pensamento único, a economia de mercado neoliberal, as novas modalidades de imperialismo "e suas consequências para o destino da humanidade" (CORTINA, 2005, p. 331). Para ela,

No plano de uma ética discursiva, o progresso econômico não pode ser apenas técnico, mas também social e, portanto, vinculado às aspirações matérias da vida baseado na cooperação produtiva e na distribuição, para que seja compatível com os ideais de liberdade, justiça, igualdade e paz. Seu pressuposto é a existência de uma teoria compartilhada de justiça distributiva, "posto que o fim social da economia é a satisfação as necessidades humanas" (tradução livre dos autores) (CORTINA, 1993, p. 226).

O segundo reivindica a antropologia cultural, naquela mesma dimensão crítica. Parte dos sociólogos Fernando Calderón, Martín Hopenhayn e Ernesto Ottone (1993), que apontam para a um amplo consenso de agentes os quais, a partir de um cenário democrático, insiste em desencadear um debate que implique envolver a capacidade de autodeterminação dos agentes sociais do desenvolvimento, num cenário em que tensão social e modernidade são os pontos cruciais a serem enfrentados. Num cenário de desigualdades, exclusão social, fome e miséria, é preciso superar a dicotomia ou a estreita vinculação entre identidade cultural e dominação.

\footnotetext{
A superação dessa dicotomia implica reconhecer a existência de um tecido intercultural que não deve ser visto como um obstáculo, mas como um potencial transformador das injustiças sociais, na medida em que seja superada a dialética da construção outro, que nega a existência de outro distinto de si - os excluídos de todo gênero - marcada pela dominação político-econômica. (Idem, p. 338).
}

Para eles, torna-se imprescindível reverter essa negação ou a discriminação do outro distinto de si e reconhecer a esse outro como parte de uma identidade coletiva que também nos inclui. Neste cenário multifacetado, metamorfoseado de relações de trabalho e de desemprego estrutural, a abrangência aqui proposta para a teoria jurídica do salário implica reverter esta negação ou esta discriminação do outro distinto de si e 
Reconhecer a esse outro como parte de uma identidade coletiva que também nos inclui, poderia chegar a ser uma forma de transmutar a negação histórica em afirmação do futuro. Obviamente, não é esta uma síntese que aparece nem espontânea nem repentinamente, mas que constitui um processo conflitivo e povoado de obstáculos. Mas o próprio processo é de enriquecimento cultural e de construção de uma cidadania comum. (Ibidem, p 338).

\section{c) O Princípio do Direito do Trabalho na Categoria de Direito Humano Fundamental.}

Uma vez alargado o campo protetivo; uma vez inserida perspectiva democrática da economia do trabalho é possível compreender a razão pela qual se insere este campo do conhecimento jurídico na categoria de Direito Humano Fundamental.

Fica clara esta dimensão teórica que questiona a versão tradicional de trabalho decente, posto que a mesma está condicionada a uma perspectiva dogmática reducionista centrada no trabalho livre/subordinado. Uma visão relaciona à proteção a todas as possibilidades e alternativas de trabalho e renda compatíveis com a dignidade humana, que inclua o trabalho envolvido com a Economia Solidária, o trabalho propriamente livre que permite ao gênero humano desfrutar de todos os bens e necessidades materiais, artísticas, culturais, dentre elas o lazer.

A filósofa Adela Cortina descreve cinco perspectivas gerais de direitos, cada um deles orientado por um valor-guia. No que concerne a uma nova concepção de cidadania, encontrase a mesma vinculada aos guias característicos de uma ética cívica,

Esta, por sua vez, sincronizada com a reconstrução dos valores culturais voltados para o trabalho. Ao trabalho desvinculado da escravidão, da dor, do sacrifício, do masoquismo, embora identificado com a criatividade, com a igualdade de oportunidades de segurança social, com a livre produção dos bens artísticos, culturais e científicos e que não seja um instrumento nas mãos dos poderosos para aumentar a concentração de riquezas, ampliar a fome e a exclusão social (CORTINA, 2008, p. 233).

Uma concepção analítica que se articula com a secção anterior para, alargando o campo de proteção e de incidência do Direito do Trabalho, poder-se repensar o próprio modelo de Sociedade de Trabalho que se pretende para o país. 


\section{CONCLUSÕES}

Uma versão analítica voltada para diagnosticar e superar as desigualdades e pensar um Brasil justo, para os especialistas da área acadêmica a que pertencem os autores deste artigo, implica adotar uma nova pauta hermenêutica e outros fundamentos teórico-filosóficos para este campo do conhecimento jurídico.

Implica também reconhecer uma articulação desta disciplina com outros campos dos chamados saberes sociais que permitam, em seu conjunto, ampliar a perspectiva da Sociedade do Trabalho a ser juridicamente envolvida com o Direito do Trabalho.

Neste sentido, apresentam as seguintes proposições:

a) Reconhecer as metamorfoses enfrentadas pela Sociedade do Trabalho contemporânea que passa a se envolver com uma heterogenização/complexificação/fragmentação do trabalho, o que implica reconhecer também uma subproletarização, ambas convivendo com o desemprego estrutural.

b) Para superar a versão tradicional da proteção vinculada ao trabalho subordinado, torna-se imprescindível incluir a Economia Social e Solidária; a Renda Garantida e a taxação das grandes fortunas, bem como reconhecer a necessidade de uma inversão paradigmática na economia política prevalecente centrada no ultraliberalismo global e num modelo de acumulação flexível de caráter destrutível.

c) Do ponto de vista da Teoria do Conhecimento Jurídico-trabalhista crítico, este artigo articula os princípios da Proteção Social, da Democratização da Economia e do Trabalho e do Direito do Trabalho na Categoria de Direito Humano Fundamental.

\section{REFERÊNCIAS}

ANTUNES, Ricardo. Os sentidos do trabalho: ensaio sobre a afirmação e a negação do trabalho. São Paulo: Boitempo, 2006.

ANDRADE, Everaldo Gaspar Lopes de Andrade. Direito do trabalho: Ensaios filosóficos, vol. 2. São Paulo: LTr, 1995.

ANDRADE, Everaldo Gaspar Lopes de. Direito do Trabalho e Pós-modernidade. Fundamentos para uma teoria geral. São Paulo: LTr, 2005. 2008 .

Princípios de Direito do Trabalho. Fundamentos teórico-filosóficos. São Paulo: LTr, 
BAUMAN, Zygmunt. A riqueza de poucos beneficia todos nós? Rio de Janeiro: Zahar, 2015. CALDERÓN, F.; HOPENHAYN, M. e OTTONI, E. Hacia una perspectiva crítica de la modernidade: las dimensiones culturales de la transformación productiva con equidade. Chile: Naciones Unidas, 1993.

DALY, Herman. Steady-State Economics. San Francisco: W. H. Freeman, 1977.

DANGELO, Isabele Bandeira de Moraes. A subordinação no direito do trabalho - para ampliar os cânones da proteção, a partir da economia social e solidária. São Paulo: LTr: 2014.

DRUCK, Graça; FRANCO, Tânia. A Perda da Razão Social do Trabalho: Terceirização e precarização. São Paulo: Boitempo, 2007. Em < http://www.bbc.com/portuguese/noticias/2015/08/150825_finlandia_minimo_tg>. Acessado em: 06 de abril de 2016.

ESTEVES, Juliana Teixeira. O Direito da Seguridade Social. A Renda Universal Garantida, a taxação dos fluxos financeiros internacionais e nova proteção social. Recife: Editora da UFPE, 2015.

LATOUCHE, Serge. Pequeno tratado sobre o decrescimento sereno. São Paulo: WMF, 2009.

MÉSZÁROS, István. A teoria da alienação em Marx. 2006, p. 27. São Paulo: Boitempo, 2006.

OLMEDO, Luiza B. A maioria dos países desenvolvidos taxa ou já taxou as grandes fortunas. Em: <http://www.sul21.com.br/jornal/a-maioria-dos-paises-desenvolvidos-taxa-ou-ja-taxouas-grandes-fortunas/>. Acessado em: 06 de abril de 2016.

OFFE, C. Trabalho \& sociedade: problemas estruturais e perspectivas para o futuro da sociedade do trabalho. Vol. 2. Rio de Janeiro: Tempos Brasileiros, 1991.

PIKETTY, Thomas. O capital no século XXI. Rio de Janeiro: Intrínseca, 2014. RAVENTÓS L. A. El derecho a la existencia. La propuesta del subsidio universal
garantizado. Barcelona: Editorial Ariel, 1999.

RODRIGUEZ, Américo Plá. Principios de Direito do Trabalho. São Paulo: LTR, 2000.

ROEGEN, Nicholas Georgescu. The Entropy Law and the Economic Process, Boston: Harvard University, 1971. 
SAVATER, Fernando en El País (2-1-2000): "La posibilidad de una renta básica de ciudadanía, entendida como un derecho social para todos, y no como mero subsidio ante la adversidad, es uno de los ideales que pueden movilizar en los próximos años tanto las conciencias éticas como los proyectos políticos. < http://www.derechoshumanos.unlp.edu.ar/assets/files/documentos/el-derecho-de-existencia-yrenta-basica-de-ciudadania-una-justificacion-republicana-maria-bertomeu-y-danielreventos.pdf>. Acessado em 08 de abril de 2016.

SANTOS, Boaventura de Souza; RODRÍGUEZ, César. Introdução: para ampliar o cânone da produção. In: SANTOS, Boaventura de Souza (Org.). Produzir para Viver. Os caminhos da produção não capitalista. Rio de Janeiro: Civilização Brasileira, 2005.

. Trabalhar o mundo. Os caminhos do novo internacionalismo operário. Rio de Janeiro: Civilização Brasileira, 2011.

SIMÃO, Vilma Margarete. As Trajetórias e o Trabalho Cooperado e Autogestor. Uma análise marxista. Blumenau: Edifurb, 2011.

World employment and social outlook: Trends 2015. (World employment and social outlook. International Labour Office. - Geneva: ILO, 2015. < http://www.ilo.org/wcmsp5/groups/public/---dgreports/---dcomm/--publ/documents/publication/wcms_337069.pdf>. Acessado em 06 de abril de 2016.) 